\title{
Antecedents and Consequences of Employee Engagement- A Hypothetical Approach
}

\author{
Mr.K.ArunKumar, Ms.R.Renugadevi \\ Assistant Professor, Department of Management Studies, M.I.E.T Engineering College, Trichy, Tamilnadu, \\ India. \\ Assistant Professor, SreeVee Business School, Dindigul, Tamilnadu, India
}

\begin{abstract}
One of the most important assets that differentiate two organizations is its Human Resources, each a unique combination of KSAs (Knowledge, Skills \& Abilities). Human resources being most important assets of any organization act as source of competitive advantage. It has become essential for the organizations to find a way to take advantage of all available manpower for the purpose of sustainment and further growth. A successful approach to any task requires combining both rational and emotional behavior. Therefore, the organization must make a deliberate effort to reach out at both levels. Only motivation does not work here, it is very important to inculcate a sense of oneness among the employees for the organization's mission and vision. This could be only possible only when their efforts could be successfully converted into commitment. To achieve this end, employee engagement is a very powerful tool available to the employers.
\end{abstract}

Keywords: Burn Out, Disengagement, Employee Engagement, Job Involvement

\section{Introduction}

Employee engagement is a key business driver for organizational success. High levels of engagement in domestic and global firms promote retention of talent, foster customer loyalty and improve organizational performance and stakeholder value. A complex concept, engagement is influenced by many factors-from workplace culture, organizational communication and managerial styles to trust and respect, leadership and company reputation. For today's different generations, access to training and career opportunities, work/life balance and empowerment to make decisions are important. Thus, to foster a culture of engagement, HR leads the way to design measure and evaluate proactive workplace policies and practices that help attract and retain talent with skills and competencies necessary for growth and sustainability.

The authors have taken up the analysis of the secondary data on Employee Engagement with the following Objectives:

1. To define Employee Engagement.

2. To study Antecedents and Consequences of Employee Engagement.

3. To analyze the Measurement issues of Employee Engagement.

4. To present an overview on researching Employee Engagement.

\section{Definitions Of Employee Engagement}

1. Kahn (1990:694) defines employee engagement as _the harnessing of organization members'selves to their work roles; in engagement, people employ and express themselves physically, cognitively, and emotionally during role performances.

2. Most often employee engagement has been defined as emotional and intellectual commitment to the organization (Baumruk 2004, Richman 2006 and Shaw 2005).

3. Truss et al (2006) define employee engagement simply as passion for work', a psychological state which is seen to encompass the three dimensions of engagement discussed by Kahn (1990), and captures the common theme running through all these definitions.

4. Harter, Schmidt and Hayes (2002) define employee engagement as "the individual's involvement and satisfaction with as well as enthusiasm for work".

5. Lucey, Bateman and Hines (2005) interpret the Gallup Engagement Index as measuring "how each individual employee connects with your company and how each individual employee connects with your customers". They call the opposite of this emotionally unemployed.

6. DDI (2005) uses the definition "The extent to which people value, enjoy and believe in what they do" (p1). DDI also states that its measure is similar to employee satisfaction and loyalty.

7. Fleming, Coffman and Harter (2005) (Gallup Organization researchers) use the term committed employees as a synonym for engaged employees. 
8. Gallup's Human Sigma website (2005) likens employee engagement to the concept of customer engagement, which has the dimensions of confidence, integrity, pride and passion.

9. Wellins and Concelman (2004) call employee engagement "the illusive force that motivates employees to higher levels of performance".

10. Robinson, Perryman and Hayday (2004) define engagement as "a positive attitude held by the employee towards the organization and its values.

11. The Business Communicator (2005)13 reports definitions of engagement from three people they label experienced employee engagement practitioners.

Those three definitions are, as follows:

1. Engagement is two sides of a coin, the knowledge needed to do one's job effectively and the motivation to apply that knowledge.

2. Increasing workforce dedication to achieve a business outcome.

3. Employee engagement is a social process by which people become personally implicated in strategy and change in their daily work.

\section{Antecedents And Consequences Of Employee Engagement}

\section{ANTECEDENTS}

\section{Job Characteristics}

Psychological meaningfulness involves a sense of return on investments of the self-in-role performances (Kahn, 1992). According to Kahn $(1990,1992)$, psychological meaningfulness can be achieved from task characteristics that provide challenging work, variety, allow the use of different skills, personal discretion, and the opportunity to make important contributions. This is based on Hackman and Oldham's (1980) 28 job characteristics model and in particular, the five core job characteristics (i.e. skill variety, task identity, task significance, autonomy, and feedback).

\section{Perceived Organizational and Supervisor Support}

Two variables that are likely to capture the essence of social support are perceived organizational support (POS) and perceived supervisor support (PSS). POS refers to a general belief that one's organization values their contribution and cares about their well-being (Rhoades and Eisenberger, 2002)30. The basic premise of organizational support research is SET. The Social Exchange Theory (SET) perspective is that employees who are provided with enriched and challenging jobs will feel obliged to respond with higher levels of engagement. SET argues that obligations are generated through a series of interactions between parties who are in a state of reciprocal interdependence.A basic principle of SET is that relationships evolve over time into trusting, loyal, and mutual commitments aslong as the parties abide by certain rules' of exchange (Cropanzano and Mitchell 2005). In particular, POS creates an obligation on the part of employees to care about the organization's welfare and to help the organization reach its objectives (Rhoades et al., 2001)31. PSS is also likely to be an important predictor of employee engagement. In fact, a lack of support from supervisors has been found to be an especially important factor linked to burnout (Maslach et al., 2001). When employees have high perceptions of justice in their organization, they are more likely to feel obliged to also be fair in how they perform their roles by giving more of themselves through greater levels of engagement.

\section{Rewards and Recognition}

Kahn (1990) reported that people vary in their engagement as a function of their perceptions of the benefits they receive from a role. Maslach et al. (2001)29 have also suggested that while a lack of rewards and recognition can lead to burnout, appropriate recognition and reward is important for engagement.

\section{Distributive and Procedural Justice}

The safety dimension identified by Kahn (1990) involves social situations that are predictable and consistent. For organizations, it is especially important to be predictable and consistent in terms of the distribution of rewards as well as the procedures used to allocate them. While distributive justice pertains to one's perception of the fairness of decision outcomes, procedural justice refers to the perceived fairness of the means and processes used to determine the amount and distribution of resources (Colquitt, 2001; Rhoades et al., 2001).

A review of organizational justice research found that justice perceptions are related to organizational outcomes such as job satisfaction, organizational commitment, organizational citizenship behavior, withdrawal, and performance (Colquitt et al., 2001). However, previous research has not tested relationships between fairness perceptions and employee engagement. 


\section{Job Satisfaction}

\section{Consequences Of Employee Engagement}

Job satisfaction, a widely researched construct, is defined as a pleasurable or positive emotional state resulting from the appraisal of one's job or job experiences (Locke \& Henne, 1986)32. It has been found that while the relationship between job satisfaction and performance is weak at the individual level, but is stronger at the aggregate level (Ostroff, 1992).

\section{Organizational Commitment}

This also differs from engagement in that it refers to a person's attitude and attachment towards their organization. Engagement is not an attitude; it is the degree to which an individual is attentive and absorbed in the performance of their roles.

\section{Intention to Quit}

Intention to quit includes basically the reasons why employees are going to quit the job, and what factors made the employee to leave the organization. The engaged employees do not frequently quit the job.

\section{Organizational Citizenship Behavior}

OCB involves voluntary and informal behaviors that can help co-workers and the organization, the focus of engagement is one's formal role performance rather than extra-role and voluntary behavior. According to Maslach et al. (2001), six areas of work-life lead to burnout and engagement: workload, control, rewards and recognition, community and social support, perceived fairness, and values. They argue that job engagement is associated with a sustainable workload, feelings of choice and control, appropriate recognition and reward, a supportive work community, fairness and justice, and meaningful and valued work. The driving force behind the popularity of employee engagement is that it has positive consequences for organizations. As indicated earlier, there is a general belief that there is a connection between employee engagement and business results (Harter et al., 2002)33. However, engagement is an individual-level construct and if it does lead to business results, it must first impact individual-level outcomes. Along these lines, there is reason to expect employee engagement to be related to individuals' attitudes, intentions, and behaviors.

\section{Measurement Issues Of Employee Engagement}

Gallup came up with a twelve-question survey that identifies strong feelings of employee engagement.

They have identified 12 questions that most effectively measure the links (the Gallup Q12).

1. Do you know what is expected of you at work?

2. Do you have the materials and equipment you need to do your work right?

3. At work, do you have the opportunity to do what you do best every day?

4. In the last seven days, have you received recognition or praise for doing good work?

5. Does your supervisor, or someone at work, seems to care about you as a person?

6. Is there someone at work who encourages your development?

7. At work, do your opinions seem to count?

8. Does the mission/purpose of your company make you feel your job is important?

9. Are your associates (fellow employees) committed to doing quality work?

10. Do you have a best friend at work?

11. In the last six months, has someone at work talked to you about your progress?

12. In the last year, have you had opportunities at work to learn and grow?

\section{The Engagement Index}

The first measurement tool is JRA six item engagement indexes. The JRA employee engagement index has been validated across many thousands of New Zealand employees since its first use in 2000 . This is a simple and focused tool that uses six items to assess the rational-emotional-behavioral components of Employee engagement. The six questionnaire items are:

- I look for ways to do my job more effectively.

- Overall, I'm satisfied with my job.

- I take an active interest in what happens in this organization.

- I feel inspired to go the extra mile to help this organization succeed.

- I feel a sense of commitment to this organization.

- Overall, I would recommend this organization as a great place to work.

The Corporate Leadership Council uses the following four questions:

- I am proud to work at COMPANY.

- Overall my satisfaction with COMPANY is high. 
- I would recommend COMPANY as a great place to work.

- If offered a similar position and compensation at another company I would stay at Company.

\section{An Overview On Researching Employee Engagement}

One of the most influential studies of engagement was carried out by Kahn (1990). Conceptually, Kahn began with the work of Goffman (1961)37 who proposed that, "people's attachment and detachment to their role varies" (Kahn 1990:694). However, Kahn argued that Goffman's work focused on fleeting face-to-face encounters, while a different concept was needed to fit organizational life, which is "ongoing, emotionally charged, and psychologically complex" (Diamond and Allcorn 1985). To gain further understanding of the varying levels of attachment individuals expressed towards their roles, Kahn (1990) examined several disciplines. It was found that psychologists (Freud 1922)39, sociologists (Goffman 1961, Merton 1957) and group theorists (Slater 196641, Smith and Berg 198742) had all recognized the idea that individuals are naturally hesitant about being members of ongoing groups and systems. As a result they "seek to protect themselves from both isolation and engulfment by alternately pulling away from and moving towards their memberships" (Kahn 1990). The terms Kahn (1990) uses to describe these calibrations are 'personal engagement' and 'personal disengagement', which refer to the "behaviors by which people bring in or leave out their personal selves during work role performances" (Kahn 1990:694). These terms developed by Kahn (1990) integrate previous ideas taken from motivation theories that people need self-expression and self-employment in their work lives as a matter of course (Alderfer 197243, Maslow 1954). Kahn undertook a qualitative study on the psychological conditions of personal engagement and disengagement by interviewing summer camp counselors and staff at an architecture firm about their moments of engagement and disengagement at work. He defined disengagement as the decoupling of the self within the role, involving the individual withdrawing and defending themselves during role performances (May et al 2004). Disengaged employees displayed incomplete role performances and were effortless, automatic or robotic (Kahn 1990). Kahn found that there were three psychological conditions related with engagement or disengagement at work: meaningfulness, safety, and availability. He argued that people asked themselves three fundamental questions in each role situation: (i) How meaningful is it for me to bring myself into this performance; (ii) How safe is it to do so? and (iii) How available am I to do so? He found that workers were more engaged at work in situations that offered them more psychological meaningfulness and psychological safety, and when they were more psychologically available.

In the only study to empirically test Kahn's (1990) model, May et al (2004) found that meaningfulness, safety, and availability were significantly related to engagement. They also found job enrichment and role fit to be positive predictors of meaningfulness; rewarding coworker and supportive supervisor relations were positive predictors of safety, while adherence to co-worker norms and self-consciousness were negative predictors. Resources were a positive predictor of psychological availability, while participation in outside activities was a negative predictor. Overall, meaningfulness was found to have the strongest relation to different employee outcomes in terms of engagement. An alternative model of engagement comes from the 'burnout' literature, which describes job engagement as the positive antithesis of burnout, noting that burnout involves the erosion of engagement with one's job (Maslach et al 2001). According to Maslach et al, six areas of work-life lead to either burnout or engagement: workload, control, rewards and recognition, community and social support, perceived fairness and values. They argue that job engagement is associated with a sustainable workload, feelings of choice and control, appropriate recognition and reward, a supportive work community, fairness and justice, and meaningful and valued work. Like burnout, engagement is expected to mediate the link between these six work-life factors and various work outcomes. May et al's (2004) findings support Maslach et al's (2001) notion of meaningful and valued work being associated with engagement, and therefore it is important to consider the concept of 'meaning'. According to Holbeche and Springett (2003)46, people's perceptions of 'meaning' with regard to the workplace are clearly linked to their levels of engagement and, ultimately, their performance.

They argue that employees actively seek meaning through their work and, unless organizations try to provide a sense of meaning, employees are likely to quit. The research findings suggest that many people experience a greater search for meaning in the workplace ( 70 per cent) than in life in general (ibid). There are numerous possible reasons for this, for example, it may be because people generally spend longer at work than on other parts of their lives. Holbeche and Springett (2003) argue that high levels of engagement can only be achieved in workplaces where there is a shared sense of destiny and purpose that connects people at an emotional level and raises their personal aspirations. Kahn's (1990) and Maslach et al's (2001) models indicate the psychological conditions or antecedents that are necessary for engagement, but they do not fully explain why individuals will respond to these conditions with varying degrees of engagement. According to Saks (2006), a stronger theoretical rationale for explaining employee engagement can be found in social exchange theory (SET). SET argues that obligations are generated through a series of interactions between parties who are in a state of reciprocal interdependence. A basic principle of SET is that relationships evolve over time into trusting, 
loyal, and mutual commitments as long as the parties abide by certain 'rules' of exchange (Cropanzano and Mitchell 2005) 47. Such rules tend to involve reciprocity or repayment rules, so that the actions of one party lead to a response or actions by the other party. For example, when individuals receive economic and socioemotional resources from their organization, they feel obliged to respond in kind and repay the organization (ibid). This is consistent with Robinson et al's (2004) description of engagement as a two-way relationship between the employer and employee. Saks (2006) argues that one way for individuals to repay their organization is through their level of engagement. In other words, employees will choose to engage themselves to varying degrees and in response to the resources they receive from their organization. Bringing oneself more fully into one's work roles and devoting greater amounts of cognitive, emotional, and physical resources is a very profound way for individuals to respond to an organization's actions, as suggested earlier by the work of Kahn (1990). Thus, employees are more likely to exchange their engagement for resources and benefits provided by their organization. In summary, Social Exchange Theory, SET provides a theoretical foundation to explain why employees choose to become more or less engaged in their work and organization. In terms of Kahn's (1990) definition of engagement, employees feel obliged to bring themselves more deeply into their role performances as repayment for the resources they receive from their organization. When the organization fails to provide these resources, individuals are more likely to withdraw and disengage themselves from their roles. Thus, the amount of cognitive, emotional, and physical resources that an individual is prepared to devote in the performance of their work role may be contingent on the economic and socioemotional resources received from the organization.

In recent years, more studies have begun to look at the antecedents and consequences of employee engagement. For example, Saks (2006) found a distinction between two types of engagement, job engagement and organization engagement, which he argues are related but distinct constructs. In addition, he argued that the relationships between both job and organization engagement, and their antecedents and consequences differed in a number of ways, suggesting that the psychological conditions that lead to job and organization engagement, as well as their consequences, is not the same. Whilst this study has provided a new insight into employee engagement, it is important to note the survey was completed by a small sample of 102 employees in Canada. Therefore, the results may not be generalisable to employees in the UK, for example, as definitions of engagement vary in different countries and national differences may play a part in what leads to engagement in the first place. Nevertheless, it adds a new insight into the existing body of literature as it is the first study to make a distinction between job and organization engagement and to measure a variety of antecedents and on sequences of job and organization engagement; previous research has focused primarily on engagement at the individual level. Practitioners and academics tend to agree that the consequences of employee engagement are positive (Saks 2006). There is a general belief that there is a connection between employee engagement and business results; a met analysis conducted by Harter et al (2002:272) confirms this connection. They concluded that, "...employee satisfaction and engagement are related to meaningful business outcomes at a magnitude that is important to many organizations". However, engagement is an individual-level construct and if it does lead to business results, it must first impact individual level outcomes. Therefore, there is reason to expect employee engagement is related to individuals' attitudes, intentions, and behaviors. Although neither Kahn (1990) nor May et al (2004) included outcomes in their studies, Kahn (1992) proposed that high levels of engagement lead to both positive outcomes for individuals, (eg quality of people's work and their own experiences of doing that work), as well as positive organizational-level outcomes (eg the growth and productivity of organizations). The Gallup organization (2004) 48 found critical links between employee engagement, customer loyalty, business growth and profitability. They compared the scores of these variables among a sample of stores scoring in the top 25 per cent on employee engagement and customer loyalty with those in the bottom 25 per cent. Stores in the bottom 25 per cent significantly under-performed across three productivity measures: sales, customer complaints and turnover. Gallup cites numerous similar examples. The International Survey Research (ISR) 49 team has similarly found encouraging evidence that organizations can only reach their full potential through emotionally engaging employees and customers (ISR 2005). In an extension of the Gallup findings, Ott (2007)50 cites Gallup research, which found that higher workplace engagement predicts higher earnings per share (EPS) among publicly-traded businesses. When compared with industry competitors at the company level, organizations with more than four engaged employees for every one actively disengaged, experienced 2.6 times more growth in EPS than did organizations with a ratio of slightly less than one engaged worker for every one actively disengaged employee. The findings can be considered as reliable as the variability in differing industries was controlled by comparing each company to its competition, and the patterns across time for EPS were explored due to a 'bouncing' increase or decrease which is common in EPS (Ott 2007). Whilst this research does not show investors and business leaders exactly what organizations are doing on a day to day basis to develop engaged employees, the findings do demonstrate differences in overall performance between companies, and Gallup's meta-analyses present strong evidence that highly engaged workgroups within companies outperform groups with lower employee engagement levels, and the recent findings reinforce these 
conclusions at the workgroup level. The meta-analysis study shows that top-quartile business units have 12 percent higher customer advocacy, 18 per cent higher productivity, and 12 per cent higher profitability than bottom-quartile business units. In contrast, bottom-quartile business units experience 31 per cent to 51 per cent more employee turnover and 62 per cent more accidents than those in the top quartile of workplace engagement. This research into EPS provides a degree of proof that employee engagement correlates to crucial business outcomes.

\section{Conclusions}

Employee engagement emphasizes the importance of employee communication on the success of a business. An organization should realize the importance of employees, more than any other variable, as the most powerful contributor to an organization's competitive position. Organizations and employees share a symbiotic relation, where both are dependent on each other to satisfy their needs and goal. Keeping this fact in mind the employers must identify the best way to utilize their talent. Surveys and researches reveal that employees could be best engaged if their unique needs could be fulfilled. It is very essential to realize what they are best at and engage their talents in the best possible way. Therefore employee engagement should not be a onetime exercise, but a continuous process of learning, improvement and action. As it is rightly said, "An empty mind is a Devil's workshop" and hence the need to engage employees in the most productive way, and gain competitive advantage.

\section{References}

[1]. Kahn, W.A. (1990) 'Psychological conditions of personal engagement and disengagement at work', Academy of Management Journal, Vol 33, pp 692-724.

[2]. Baumruk, R. (2004) 'the missing link: the role of employee engagement in business successes, Workspan, Vol 47, pp 48-52.

[3]. Richman, A. (2006) 'Everyone wants an engaged workforce how can you create it?'Workspan, Vol 49, pp 36-39.

[4]. Shaw, K. (2005) 'An engagement strategy process for communicators', Strategic Communication Management, Vol 9, No 3, pp 2629.

[5]. Truss, C., Soane, E., Edwards, C., Wisdom, K., Croll, A. and Burnett, J. (2006) Working Life: Employee Attitudes and Engagement 2006. London, CIPD.

[6]. Harter, J.K., F.L. Schmidt \& T.L. Hayes (2002), 'Business-unit-level relationship between employee satisfaction, employee engagement, and business outcomes: A meta-analysis'. Journal of Applied Psychology, Vol 87, No.2, pp 268-279.

[7]. Lucey, J. N. Bateman \& P. Hines. (2005). 'Why major lean transitions have not been sustained'. Management Services, Vol 49, No.2, pp 9-14

[8]. Development Dimensions International (DDI). (2005). Whitepaper--Driving Employee Engagement. November 11, 2012, from www.ddiworld.com

[9]. Fleming, J.H., C. Coffman \& J.K. Harter (2005). 'Manage your human Sigma'. Harvard Business Review, Vol 83, No.7, pp 106-115.

[10]. The Gallup Organization (2005). Employee Engagement: The Employee side of the Human Sigma Equation. Retrieved November 11, 2012, from http://www.gallup.com/content/default.aspx?ci=52.

[11]. Wellins, R. \& J. Concelman. (2005). Creating a culture for engagement. Workforce Performance Solutions. Retrieved November 11, 2012 from www.WPSmag.com.

[12]. Robinson, D., S. P. Perryman \& S. Hayday. (2004). The Drivers of Employee Engagement. IES Report 408. Retrieved November 11, 2012, from http://www.employment-studies.co.uk/summary/ summary.php?id=408

[13]. Anonymous (2005). 'What does employee engagement look like?', The Business Communicator, Vol 5, No.8, pp 1-2.

[14]. Saks, A.M. (2006) 'Antecedents and consequences of employee engagement', Journal of Managerial Psychology, Vol 21, No 6, pp 600-619.

[15]. May, D.R. Gilson, R.L. and Harter, L.M. (2004) 'The psychological conditions of meaningfulness, safety and availability and the engagement of the human spirit at work', Journal of Occupational and Organisational Psychology, Vol 77, pp11-37.

[16]. Kanungo, R.N. (1982) 'Measurement of job and work involvement', Jourmal of Applied Psychology, Vol 67, pp 341-349

[17]. Harter, J.K., F.L. Schmidt \& T.L. Hayes (2002). 'Business-unit-level relationship between employee satisfaction, employee engagement, and business outcomes: A meta-analysis’. Journal of Applied Psychology, Vol 87,No.2, pp 268-279

[18]. Ostroff, C. (1992). 'The relationship between satisfaction, attitudes and performance: An organizational level analysis'. Journal of Applied Psychology, Vol 77, No.3, pp 963-974.

[19]. Paullay, I.M., G.M. Alliger \& E.F. Stone-Romero (1994). 'Construct validation of two instruments designed to measure job involvement and work centrality’. Journal of Applied Psychology, Vol 79, No.2, pp 224-228.

[20]. Diefendorff, M.M., D.J. Brown, A.M. Kamin, \& R.G. Lord (2002). 'Examining the roles of job involvement and work centrality in predicting organizational citizenship behaviors and job performance'. Journal of Organizational Behavior, Vol 23, No. 1, pp. 93-108.

[21]. Wellins, R. \& J. Concelman. (2005). Creating a culture for engagement. Workforce Performance Solutions. Retrieved November 11, 2012 from www.WPSmag.com.

[22]. Maslach, C., Schaufelli, W.B. and Leiter, M.P. (2001), "Job burnout”, Annual Review of Psychology, Vol. 52, pp. 397-422.

[23]. Rhoades, L. and Eisenberger, R. (2002), "Perceived organizational support: a review of the literature", Journal of Applied Psychology, Vol. 87, pp. 698-714.

[24]. Rhoades, L., Eisenberger, R. and Armeli, S. (2001), "Affective commitment to the organization: the contribution of perceived organizational support”, Journal of Applied Psychology,Vol. 86, pp. 825-36. 